\title{
Development of Cleruchoides noackae, an egg-parasitoid of Thaumastocoris peregrinus, in eggs laid on different substrates, with different ages and post-cold storage
}

\author{
Leonardo Rodrigues Barbosa • Ângelo Peruffo Rodrigues • Lohana Neves de Souza • \\ Luís Amilton Foerster • Amanda Rodrigues de Souza • Bárbara Monteiro de Castro e Castro • \\ Carlos Frederico Wilcken · José Cola Zanuncio
}

Received: 31 March 2017 / Accepted: 11 December 2017 / Published online: 24 January 2018

(C) International Organization for Biological Control (IOBC) 2018

\begin{abstract}
Cleruchoides noackae Lin and Huber (Hymenoptera: Mymaridae) is an egg parasitoid of Thaumastocoris peregrinus Carpintero and Dellapé (Hemiptera: Thaumastocoridae). The parasitism and development of $C$. noackae was studied in $T$. peregrinus eggs of different ages, laid on eucalyptus leaves or paper towel and stored at $5{ }^{\circ} \mathrm{C}$. The emergence, sex ratio and development of $C$. noackae and hatched nymphs of $T$. peregrinus were evaluated. This parasitoid had an emergence rate higher than $60 \%$ from
\end{abstract}

Handling Editor: Stefano Colazza.

L. R. Barbosa $(\bowtie)$ · Â. P. Rodrigues · L. N. de Souza Empresa Brasileira de Pesquisa Agropecuária - Embrapa Florestas, Colombo, Paraná 83411-000, Brazil

e-mail: leonardo.r.barbosa@embrapa.br

L. A. Foerster

Departamento de Zoologia, Universidade Federal do Paraná, Curitiba, Paraná 81531-990, Brazil

A. R. de Souza · C. F. Wilcken

Departamento de Proteção Vegetal, Faculdade de Ciências Agronômicas Botucatu, UNESP (Universidade

Estadual Paulista), São Paulo 18610-307, Brazil

B. M. de Castro e Castro

Departamento de Fitotecnia, Universidade Federal de Viçosa, Viçosa, Minas Gerais 36570-900, Brazil

\section{J. C. Zanuncio}

Departamento de Entomologia/BIOAGRO, Universidade Federal de Viçosa, Viçosa, Minas Gerais 36570-900, Brazil zero to one, one to two, and two to three-day old eggs and lower than $10 \%$ for those 3-4 and 4-5 days old. The female proportion was $78 \%$ and the egg-adult period for C. noackae was 19.5 days. The use of $T$. peregrinus eggs up to three days old, laid on paper towel and stored at $5{ }^{\circ} \mathrm{C}$ for 14 days did not affect the biological parameters of $C$. nockae and should be used for mass rearing of this parasitoid.

Keywords Biological control - Eucalyptus . Hemiptera $\cdot$ Hymenoptera $\cdot$ Mymaridae · Thaumastocoridae

\section{Introduction}

Thaumastocoris peregrinus Carpintero and Dellapé (Hemiptera: Thaumastocoridae), native to Australia, has been introduced and caused damage to eucalyptus trees in several countries around the world (Jacobs and Neser 2005; Laudonia and Sasso 2012; Souza et al. 2016). The management of T. peregrinus in Eucalyptus spp. plantations includes classical biological control (Reis et al. 2012; Mutitu et al. 2013). This method is important to manage exotic pests in eucalyptus plantations with introduced natural enemies (Reis et al. 2012). The parasitoid Cleruchoides noackae Lin and Huber (Hymenoptera: Mymaridae), found parasitizing eggs of the bronze bug $T$. peregrinus in Australia (Lin et al. 2007), is the main control 
agent for this insect (Souza et al. 2016). The Mymaridae family includes the smallest egg parasitoids amongst insects (Huber 1986). C. noackae was introduced into Brazil in 2012, and has been reared and released to manage $T$. peregrinus. The percentage of bronze bug eggs parasitized by $C$. noackae at release sites is close to $50 \%$ and the establishment of this natural enemy in the field was confirmed in Brazil (Barbosa et al. 2017).

Beneficial insect rearing depends on synchronization between the natural enemy, the host insect, and the plant or artificial diet, which must be studied to produce these organisms (Pratissoli et al. 2004; Silva et al. 2009; Parra 2010). The volume, surface odor, thickness, and chorion hardness, nutritional content, age, and distribution of host eggs and oviposition substrate, may affect the number, parasitism, quality, and sex ratio of natural enemies as recorded for Trichogramma spp. (Schmidt 1994; Liu et al. 1998).

Adequate egg age can improve parasitoid colonization and establishment, resulting in greater pest suppression as reported for Lobesia botrana Denis and Schiffermüller (Lepidoptera: Tortricidae) (Pizzol et al. 2012), Leptoglossus occidentalis Heidemann (Heteroptera: Coreidae) (Peverieri et al. 2013) and Chilo suppressalis Walker (Lepidoptera: Pyralidae) (Zhang et al. 2014). The quality of the nutritive resources decreases with host embryo development. This reduces offspring and foraging of adult parasitoids (Zhou et al. 2014), as reported for C. noackae on T. peregrinus eggs on eucalypt leaves (Mutitu et al. 2013). This parasitoid is reared in the laboratory with T. peregrinus eggs on paper strips, i.e., different to natural conditions, where the eggs are grouped, preferably, on eucalyptus leaves. The possible effect of this substrate on the parasitism of $C$. noackae needs to be better studied (Barbosa et al. 2016).

Pest egg storage at low temperatures is important for integrated pest management and allows the mass rearing of parasitoids in the laboratory for field release. The efficiency of this method has been studied for parasitoids such as Gonatocerus ashmeadi Girault (Hymenoptera: Mymaridae) (Chen and Leopold 2007), Tetrastichus brontispae Ferriere (Hymenoptera: Eulophidae) (Liu et al. 2014), Trichogramma spp. (Hymenoptera: Trichogrammatidae) (Spínola-Filho et al. 2014) and Gryon pennsylvanicum Ashmead (Hymenoptera: Platygastridae) (Peverieri et al. 2015).
The introduction of new biological control agents can be inhibit due to inability to rear them in the laboratory. Thus, the objective was to evaluate the substrate effects on the $C$. noackae parasitism and the development and emergence of this parasitoid in $T$. peregrinus eggs of different ages and under coldstorage and post-storage conditions.

\section{Materials and methods}

Parasitoid and host

Cleruchoides noackae rearing was initiated with individuals from a colony with specimens introduced from Australia in 2012. This parasitoid was reared on T. peregrinus eggs at $24 \pm 2{ }^{\circ} \mathrm{C}, 70 \pm 10 \% \mathrm{RH}$ and L:D 12:12 photoperiod in polystyrene flasks $(7.0 \mathrm{~cm}$ in length and $3.0 \mathrm{~cm}$ in diameter) with $50 \%$ honey solution on filter paper strips $(0.5 \times 5 \mathrm{~cm})$. Parasitoids aged between 12 and $24 \mathrm{~h}$ post-emergence were used with $T$. peregrinus eggs. This insect was reared in the laboratory at $24 \pm 2{ }^{\circ} \mathrm{C}, 60 \pm 10 \% \mathrm{RH}$ and L:D 12:12 photoperiod, from insects collected in the field. This stinkbug was kept in a bouquet of eucalyptus branches secured with a piece of foam, to prevent its being submerged (Millar et al. 2000) in a $500 \mathrm{ml}$ Erlenmeyer flask filled with water. New bouquets were put in contact with the old ones, every two days, and the latter removed when the insects migrated to the new leaves. Paper towel strips, with depressions to stimulate egg laying due to preference of this insect to oviposit near the main vein, in the grooves and depressions of the eucalyptus leaves, were used among the bouquets as a substrate for $T$. peregrinus oviposition. The $T$. peregrinus eggs were obtained, preferably from the paper strips placed in the eucalyptus bouquets, as they dried and most insects began to search for fresh food. The paper strips with egg masses were removed daily. A portion was stored at $5{ }^{\circ} \mathrm{C}$ for rearing of the parasitoid and the remaining eggs were used in the experiments. Eggs on eucalyptus leaves were used to evaluate the effect of the host substrate on parasitism. Eucalyptus benthamii plants were cultivated in the field and branches of two-yearold plants were used in laboratory tests. 
Effect of host egg substrate

Ten zero to 24-hour old $T$. peregrinus eggs obtained from eucalyptus leaves and from paper towel strips were exposed to 24-hour-old paired $C$. noackae females in either choice or non-choice tests. The female was placed at the center of a Petri dish $(5 \mathrm{~cm}$ diameter) using a fine brush. Filter paper strips $(0.5 \times 1 \mathrm{~cm})$, moistened in $50 \%$ honey solution, were used as food for the parasitoid and the dishes were closed and sealed with Parafilm ${ }^{\circledR}$. After $24 \mathrm{~h}$, the parasitoids were removed, the eggs transferred to a polystyrene vial $(7.0 \mathrm{~cm}$ long and $3.0 \mathrm{~cm}$ in diameter) and kept in an air-conditioned room at $24 \pm 2{ }^{\circ} \mathrm{C}$ and $70 \pm 10 \% \mathrm{RH}$, photoperiod of L:D 12:12, until emergence of the parasitoid adults. Thaumastocoris peregrinus nymphs, hatched from non-parasitized eggs, were removed and counted. Sixteen replications with ten eggs each were used per oviposition substrate.

Host age effect

Five age classes of $T$. peregrinus eggs (0-1, 1-2, 2-3, $3-4$, and 4-5 days), obtained on paper towel strips, were exposed to a 24-hour old parasitoid couple in a polystyrene vial $(7.0 \mathrm{~cm}$ long and $3.0 \mathrm{~cm}$ in diameter) for $24 \mathrm{~h}$. After this period, the parasitoids were removed and the eggs kept in an air-conditioned room at $24 \pm 2{ }^{\circ} \mathrm{C}, 70 \pm 10 \% \mathrm{RH}, \mathrm{L}: \mathrm{D}$ 12:12 photoperiod. Filter paper strips $(0.5 \times 3 \mathrm{~cm})$ moistened in $50 \%$ honey solution were used to feed the parasitoid. Twelve replications with ten eggs per egg age class were used.

Host egg storage at low temperature

Ten, zero to 24-hour old $T$. peregrinus eggs were collected and stored in polystyrene vials $(7.0 \mathrm{~cm}$ long and $3.0 \mathrm{~cm}$ in diameter) for 14 days at $5{ }^{\circ} \mathrm{C}$. After storage, a parasitoid couple ( $24 \mathrm{~h}$ old) was placed in the vial for $24 \mathrm{~h}$. Filter paper strips $(0.5 \times 3 \mathrm{~cm})$, moistened in $50 \%$ honey solution, were used to feed the parasitoid. The parasitoids were removed and the eggs kept in an air-conditioned room at $24 \pm 2{ }^{\circ} \mathrm{C}$, $70 \pm 10 \%$ RH, L:D 12:12 photoperiod, under the same conditions as the control. Fifteen replications with ten eggs each were used.
Host eggs post-storage at low temperature effect on C. noackae parasitism

Twelve days after storage at $5{ }^{\circ} \mathrm{C}$, ten $T$. peregrinus eggs were kept in a polystyrene vial $(7.0 \mathrm{~cm}$ long and $3.0 \mathrm{~cm}$ in diameter) in an air-conditioned room at $24 \pm 2{ }^{\circ} \mathrm{C}, 70 \pm 10 \% \mathrm{RH}$, photoperiod of L:D 12:12) and zero, one, two, three, and four days after being removed from storage at low temperature, a $C$. noackae couple ( $24 \mathrm{~h}$ old) was placed per vial for 24 $\mathrm{h}$. This process was repeated ten times per egg age.

Parameters evaluated

The parasitism percentage ((total number of parasitoids emerged + number of parasitoids retained in the egg)/ number of host eggs $\times 100$ ), development period (eggadult) and sex ratio (number of + /number of $\hat{\jmath}++$ ) of C. noackae and the percentage of T. peregrinus nymphs hatched were evaluated in the four tests. The sex ratio and the development period (egg-adult) of the parasitoid were not evaluated in the test conducted on three to four and four to five-day old host eggs and on the effect of the post egg storage period of the host parasitism by $C$. noackae on two, three and four-day old eggs, due to the low number of parasitoids emerged from the eggs (six and five individuals for three to four and four to five-day old and two, zero and six individuals for two, three and four day old post-storage eggs). The sex ratio was evaluated in the replicates in which adults emerged.

Data analysis

Parasitism, sex ratio of parasitoid and nymphs hatched were analyzed by generalized linear models (GLM) with Binomial (logit link function) distribution of error, accounting for over-dispersion (Hinde and Demétrio 1998). The parasitoid development time was analysed with Gaussian (identity link function) distribution. The fit quality of the model adjusted was evaluated based on the half-probability plot with a simulation envelope (Demétrio and Hinde 1997), using the hnp function from the hnp package in $\mathrm{R}$ (Demétrio et al. 2014). Tukey multiple comparison test $(P<0.05)$ were done by the $g l h t$ function from the multcomp package in the case of differences between treatments (Hothorn et al. 2008). Statistical analysis was done using $\mathrm{R}$ language, version 3.3.2 ( $\mathrm{R}$ Core Team 2016). 


\section{Results}

Host substrate effect

The parasitism of $T$. peregrinus eggs with $\left(F_{1,30}=0.0049, \quad P=0.9449\right)$ or without $\left(F_{1,30}=\right.$ 2.9081, $P=0.0984)$ choice, the development period (egg-adult) (with: $F_{1,30}=0.7515, P=0.3929$ and without choice: $\left.F_{1,30}=0.2727, P=0.6053\right)$ and sex ratio (with: $F_{1,30}=0.0041, P=0.9493$ and without choice: $F_{1,30}=1.1355, P=0.2951$ ) of $C$. noackae were similar between the substrates, eucalyptus leaves, and paper towel (Tables 1,2). The percentage of $T$. peregrinus nymphs on eucalyptus leaves and paper towel did not differ in the test with $\left(F_{1,30}=0.2209, \quad P=0.6418\right) \quad$ or without $\left(F_{1,30}=0.0468, P=0.8301\right)$ choice with eucalyptus leaves and paper towel (Table 2).

Host age effect

Parasitism by $C$. noackae $\left(F_{4,55}=59.742, P<0.001\right)$ was higher in $T$. peregrinus eggs with $0-1,1-2$, and 2-3 days old than in three to four and four to five-day old eggs. The number of $T$. peregrinus eggs, parasitized by $C$. noackae, was inversely related to the host egg age (Fig. 1), with a higher value for those $0-1$ $(62.50 \pm 3.92 \%), 1-2(61.66 \pm 3.65 \%)$ and $2-3$ $(62.50 \pm 2.50 \%)$ days old, followed by those with $3-4(5.0 \pm 2.88 \%)$ and $4-5(5.00 \pm 1.94 \%)$ days (Fig. 1a). The development period (egg to adult) for $C$. noackae did not differ between zero and one, one and two, and two to three-day old eggs $\left(F_{2,33}=1.5053\right.$, $P=0.2368$ ), with a mean of $15.97 \pm 0.16$; $15.71 \pm 0.15$ and $16.09 \pm 0.15$ days, respectively (Fig. 1b).

The sex ratio of $C$. noackae emerged from zero to one, one to two, and two to three-day old eggs was similar $\left(F_{2,33}=0.0817, P=0.9217\right)$, with a mean proportion of $0.78 \%$ females in the three age classes (Fig. 1c). The percentage of $T$. peregrinus nymphs hatched from eggs with $0-1, \quad 1-2$, and $2-3$ days $\quad(5.00 \pm 1.94 \%$, $7.50 \pm 2.5 \%$ and $6.67 \pm 3,33 \%$, respectively), was similar and lower than that from three to four, and four to five day old eggs $\left(F_{4,55}=65.575, P<0.001\right)$, which were similar to each other, $71.66 \pm 4.74 \%$ and $60.83 \pm 4.68 \%$, respectively (Fig. 1d).

Effect of host egg post-storage at low temperatures on C. noackae parasitism

The percentage of $T$. peregrinus eggs either fresh or following storage at $5{ }^{\circ} \mathrm{C}$ for 14 days parasitized by $C$. noackae was similar: $42.00 \pm 6.26 \%$ and $30.67 \pm$ $4.83 \%$, respectively $\left(F_{1,28}=2.0578, P=0.1625\right)$. The $C$. noackae sex ratio did not differ for parasitoids emerged from either fresh $(0.69 \pm 0.09 \%)$ or stored $(0.53 \pm 0.09 \%) T$. peregrinus eggs $\left(F_{1,26}=1.1994\right.$, $P=0.2835)$. The percentage of $T$. peregrinus nymphs hatched from fresh eggs $(32.67 \pm 7.27 \%)$ was higher than for those cold stored for 14 days $(10.00 \pm 3.52 \%)\left(F_{1,28}=23.941, P=0.001\right)$.

Post-storage period at low temperature for host eggs on C. noackae parasitism

The percentage of $T$. peregrinus eggs parasitized by $C$. noackae was lower for those with two days post storage at $5{ }^{\circ} \mathrm{C}\left(F_{4,45}=21.011, P<0.001\right)$. Cleruchoides nockae parasitized the highest number of eggs with zero $(50.00 \pm 10.65 \%)$ and one $(54.00 \pm$ $9.21 \%)$ day old. The sex ratio $\left(F_{1,16}=2.5258\right.$, $P=0.1316)$ and the development period (egg-adult) $\left(F_{1,16}=0.9537, P=0.3433\right)$ did not differ for these periods. The percentage of hatched $T$. peregrinus nymphs increased $\left(F_{4,45}=40.937, P<0.001\right)$ in eggs at two, three and four days post storage $(92.00 \pm 3.27 \%, \quad 92.00 \pm 2.91 \%$ and $90.00 \pm$ $2.98 \%$, respectively) compared with eggs at zero and

Table 1 Parasitism and sex ratio (\% female) (mean \pm SE) of Cleruchoides noackae (Hymenoptera: Mymaridae) on Thaumastocoris peregrinus (Hemiptera: Thaumastocoridae) eggs offered on eucalyptus leaves or paper towel in choice and non-choice tests

\begin{tabular}{llllll}
\hline & \multicolumn{2}{l}{ No choice } & & & \multicolumn{2}{l}{ Choice } \\
\cline { 2 - 3 } \cline { 5 - 6 } & Parasitism (\%) & Sex ratio & & Parasitism (\%) & Sex ratio \\
\hline Leaves & $61.25 \pm 4.17$ & $0.67 \pm 0.04$ & & $46.87 \pm 5.90$ & $0.76 \pm 0.04$ \\
Paper & $70.00 \pm 3.03$ & $0.74 \pm 0.05$ & $46.25 \pm 6.76$ & $0.82 \pm 0.03$ \\
\hline
\end{tabular}


Table 2 Development period (egg-adult) (Per.) of Cleruchoides noackae (Hymenoptera: Mymaridae) and percentage of Thaumastocoris peregrinus (Hemiptera: Thaumastocoridae) eggs in which nymphs hatched (Nin.) (mean \pm SE) after exposed to parasitoid on eucalyptus leaves and paper towel in choice and non-choice tests

\begin{tabular}{|c|c|c|c|c|}
\hline & \multicolumn{2}{|l|}{ No choice } & \multicolumn{2}{|l|}{ Choice } \\
\hline & Per. (days) & Nin. (\%) & Per. (days) & Nin. (\%) \\
\hline Leaves & $17.50 \pm 0.18$ & $20.62 \pm 3.92$ & $17.38 \pm 0.18$ & $33.12 \pm 5.61$ \\
\hline Paper & $17.63 \pm 0.15$ & $19.37 \pm 4.23$ & $17.69 \pm 0.31$ & $28.75 \pm 7.35$ \\
\hline
\end{tabular}

Fig. 1 Parasitism (a), development period (eggadult) (b) and sex ratio (c) of Cleruchoides noackae (Hymenoptera: Mymaridae) and percentage of nymphs hatched (d) (mean $\pm \mathrm{SE}$ ) from eggs of different ages of Thaumastocoris peregrinus (Hemiptera: Thaumastocoridae). Bars with different letters, per parameter, differ by Tukey test $(P<0.05)$
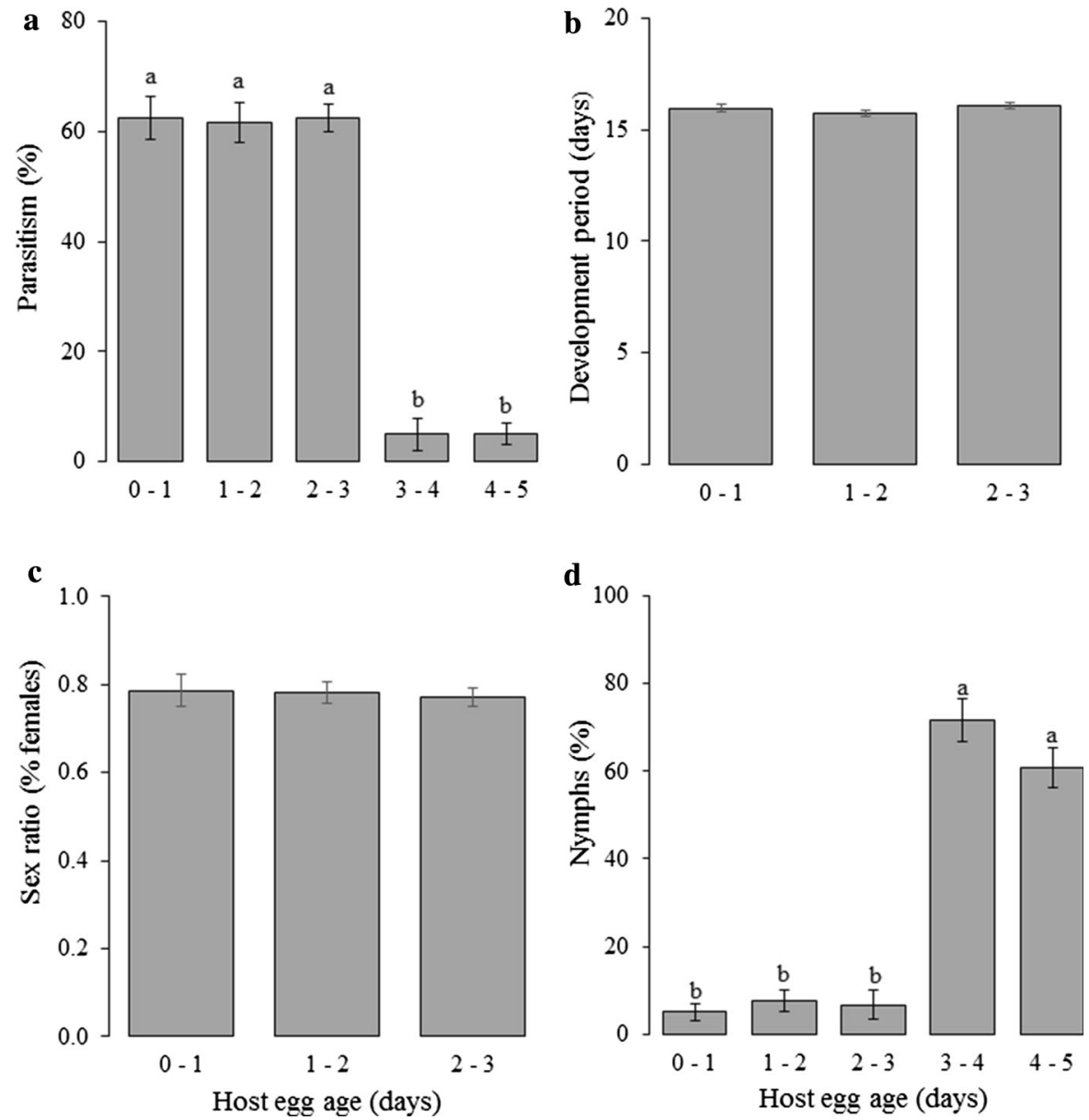

one day $(41.00 \pm 11.87 \%$ and $37.00 \pm 11.16 \%$, respectively) old (Table 3 ).

\section{Discussion}

The similar developmental period (egg-adult), sex ratio, and parasitism of $C$. nockae among $T$. peregrinus oviposition substrates suggests that the short-distance host location of this parasitoid is not related exclusively to chemical signals associated with the egg substrate as reported for other oophagous parasitoids (Colazza et al. 2014). However, this may be common for parasitoids such as Trichogramma dendrolimi Matsumura (Hymenoptera: Trichogrammatidae) on Ostrinia furnacalis Guenée (Lepidoptera: Pyralidae) eggs on pieces of paper and Zea mays L. cultivar SiDan-Ba leaves (Liu et al. 1998). During the initial 
Table 3 Parasitism, sex ratio (\% female) and development period (egg-adult) (Per.) (mean $\pm \mathrm{SE}$ ) of Cleruchoides noackae (Hymenoptera: Mymaridae) and percentage of nymphs hatched (Nin.) on Thaumastocoris peregrinus (Hemiptera: Thaumastocoridae) eggs offered one, two, three and four days after 12 days storage at $5{ }^{\circ} \mathrm{C}$ (DPA)

\begin{tabular}{|c|c|c|c|c|}
\hline DPA & Parasitism (\%) & Sex ratio & Per. (days) & Nin. (\%) \\
\hline Control & $50.00 \pm 10.65^{\mathrm{a}}$ & $0.74 \pm 0.10^{\mathrm{a}}$ & $16.78 \pm 0.14^{\mathrm{a}}$ & $41.00 \pm 11.87^{b}$ \\
\hline 1 & $54.00 \pm 9.21^{\mathrm{a}}$ & $0.59 \pm 0.04^{\mathrm{a}}$ & $16.59 \pm 0.12^{\mathrm{a}}$ & $37.00 \pm 11.16^{\mathrm{b}}$ \\
\hline 2 & $2.00 \pm 2.00^{\mathrm{b}}$ & & & $92.00 \pm 3.27^{\mathrm{a}}$ \\
\hline 3 & $0.00 \pm 0.00^{\mathrm{b}}$ & & & $92.00 \pm 2.91^{\mathrm{a}}$ \\
\hline 4 & $5.00 \pm 2.69^{\mathrm{b}}$ & & & $90.00 \pm 2.98^{\mathrm{a}}$ \\
\hline
\end{tabular}

Means per column and parameter, followed by the same letter, do not differ by Tukey test $(P<0.05)$

stage of the host location process, many parasitoids respond to air-borne chemical cues (generally highly detectable but with low reliability). On the other hand, substrate-borne chemical cues (generally low detectability but highly reliable) become progressively more important after parasitoids have landed on a host-infested patch (Vet and Dicke 1992; Fatouros et al. 2008; Colazza et al. 2014). Both substrates exposed to $T$. peregrinus oviposition were kept in direct contact with the pest in the same conditions indicating that the chemical signals left by the hosts are more important than the plant tissue for C. noackae finding its host.

The percentage of $T$. peregrinus nymphs on eucalyptus leaves and paper towel was similar showing that the substrate did not influence this biological parameter and eggs offered to C. noackae had good quality. Suitable oviposition substrates are also important to produce predatory bugs in the laboratory (Lundgren 2011) and were studied for Macrolophus caliginosus Wagner (Heteroptera: Miridae) (Constant et al. 1996; Castañé and Zapata 2005), Orius laevigatus (Hemiptera: Anthocoridae) (Bonte and De Clercq 2010; De Puysseleyr et al. 2014) and Nesidiocoris tenuis (Heteroptera: Miridae) (De Puysseleyr et al. 2013). The paper towel did not reduce $C$. noackae parasitism and can be used as a substrate to obtain $T$. peregrinus eggs, facilitating mass rearing of this parasitoid for field release.

The preference for younger $T$. peregrinus eggs shows that this parameter can affect parasitism, developmental time, emergence and sex ratio of parasitoids (Vinson 1998; Brodeur and Boivin 2004). The host egg age is important to provide nutritional resources of good quality for parasitoid offspring success (Zhou et al. 2014). The drastic reduction of the $C$. noackae parasitism rate with increasing $T$. peregrinus egg age is a common pattern for Trichogramma spp. (Liu et al. 1998; Pak et al. 1986) and Mymaridae species such as Gonatocerus triguttatus Girault parasitizing eggs of Homalodisca vitripennis Germar (syn. Coagulata) (Hemiptera: Cicadellidae) (Irvin and Hoddle 2005). The low emergence of parasitoids from older eggs may be related to the advanced stage of host embryonic development, which hampers feeding (Strand 1986). However, preference for host eggs at a given age may limit parasitoid efficiency in the field by reducing parasitism (Liu et al. 1998; Pak et al. 1986). Therefore, parasitoids that can develop in hosts of different ages may be more efficient in the field (Song et al. 2015).

Parasitism of $T$. peregrinus eggs up to three days old $(62.50 \pm 2.50 \%)$ by $C$. noackae was higher than with zero to one-day old eggs of this host $(34.1 \pm 8.6 \%)$ for this natural enemy without choice in South Africa (Mutitu et al. 2013) These differences can be attributed to the methodology, materials and processes used as well as to the population and/or strain origin as this has been shown for Trichogramma chilonis Ishii (Hymenoptera: Trichogrammatidae), $T$. ostriniae, and T. japonicum with Chilo suppressalis Walker (Lepidoptera: Crambidae) (Ko et al. 2014). The host density may influence the parasitism rate as this has been shown for Diaeretiella rapae (Hymenoptera: Braconidae) at higher densities of the host Brevicoryne brassicae L. (Hemiptera: Aphididae) (Kant and Minor 2017). The higher parasitoid density may also influence the parasitism rate (Pereira et al. 2010). Parasitoids foraging together increase the frequency of encounters between females, which can 
affect foraging efficiency (Lynch et al. 1998; Hassell 2000; Kristoffersen et al. 2001; Elliott 2003), thus reducing parasitism. The highest percentage of parasitism and emergence of $C$. noackae from $T$. peregrinus eggs with a maximum age of three days shows the importance of their use to produce this natural enemy for biological control programs.

The development of $C$. noackae in zero to one, one to two, and two to three-day old $T$. peregrinus eggs was similar to that reported for this parasitoid with 0-1, 2-3, and 4-5 days old eggs of this host in South Africa (Mutitu et al. 2013). Younger eggs appear to be more suitable for progeny development, as demonstrated for egg parasitoids such as Trichogramma japonicum Ashmead (Hymenoptera: Trichogrammatidae) on eggs of Chilo suppressalis Walker (Lepidoptera: Crambidae) (Zhang et al. 2014) and $T$. leucaniae Pang and Chen and T. chilonis Ishii on those of Leguminivora glycinivorella Matsumura (Lepidoptera: Tortricidae) (Song et al. 2015). The lack of development of $C$. noackae in 3-4 and 4-5 day old $T$. peregrinus eggs shows a reduction in the quality and availability of food due to the transformation of nutrients into more complex substrates (Vinson 1998).

The parasitoid offspring sex ratio, usually, decreases as host quality increases (King 1987). Fewer female eggs being laid indicates a decrease in acceptance levels of older host eggs resulting in an increase in offspring sex ratio (Sousa and Spence 2001). The similar sex ratio of $C$. noackae from $T$. peregrinus eggs of different ages agrees with that reported for Homalodisca vitripenis Say (Hemiptera: Cicadellidae) eggs parasitized by Gonatocerus triguttatus Girault (Hymenoptera: Mymaridae) (Irvin and Hoddle 2005) and G. deleoni Triapsitsyn, Logarzo and Virla (Hymenoptera: Mymaridae) (Lytle et al. 2012). No change in sex allocation between host age classes was observed, presumably due to acceptance levels being similar between treatments. Host egg age may be a relatively unimportant determinant of sex allocation for $C$. noackae in relation to other factors.

The increase in the percentage of hatched $T$. peregrinus nymphs as the parasitism rate on older eggs decreased is similar to that reported for Homalodisca vitripennis Germar (syn. Coagulata) (Hemiptera: Cicadellidae) nymphs hatched from ten day old eggs compared to younger ones after parasitism by Gonatocerus ashmeadi Girault (Hymenoptera: Mymaridae) (Irvin and Hoddle 2005). This result is expected because older eggs have a lower parasitism rate by $C$. noackae.

The similar parasitism of $T$. peregrinus eggs by $C$. noackae after storage at $5{ }^{\circ} \mathrm{C}$ for 14 days shows that the egg quality of this host can be maintained poststorage at this temperature. Leptoglossus occidentalis Heidemann (Heteroptera: Coreidae) eggs can be stored for longer periods at ultra-low temperatures $\left(-80\right.$ and $\left.-140{ }^{\circ} \mathrm{C}\right)$ and for shorter periods at $4{ }^{\circ} \mathrm{C}$ without affecting the fitness of the parasitoid Gryon pennsylvanicum Ashmead (Hymenoptera: Platygastridae) (Peverieri et al. 2015). Eggs of Homalodisca coagulata Say (Hemiptera: Cicadellidae), Nezara viridula L. (Hemiptera: Pentatomidae), and Sitoraga cerealella Olivier (Lepidoptera: Gelechiidae) stored up to one month at +8 or $+10{ }^{\circ} \mathrm{C}$, remained suitable for rearing Gonatocerus ashmeadi Girault (Hymenoptera: Mymaridae), Trissolcus basalis Wollaston (Hymenoptera: Platygastridae) and Trichogramma pretiosum Riley (Hymenoptera: Trichogrammatidae), respectively (Corrêa-Ferreira and Moscardi 1993; Greco and Stilinovic 1998; Chen and Leopold 2007). This strategy can be used to obtain a large number of high quality parasitoids, when required. However, storage may reduce the natural enemy ability as reported for Trichogramma ostriniae Pang and Chen (Hymenoptera: Trichogrammatidae) (St-Onge et al. 2016) and G. ashmeadi (Chen and Leopold 2007). Therefore, the success of storing host eggs by cooling or freezing appears to be dependent upon the host/parasite combination.

Thaumatocoris peregrinus eggs stored at low temperatures did not affect the sex ratio of $C$. noackae agreeing with that observed for Tetrastichus brontispae (Ferriere) (Hymenoptera: Eulophidae) (Liu et al. 2014), but this varies with parasitoid species (Ayvaz et al. 2008). Eggs of Riptortus pedestris (= clavatus) Fabricius (Hemiptera: Alydidae) can be stored at $2{ }^{\circ} \mathrm{C}$ for up to two months without affecting the sex ratio of the egg parasitoid Ooencyrtus nezarae Ishii (Hymenoptera, Encyrtidae) (Alim and Lim 2009). Further, the parasitoid Trissolcus nigripedius Nakagawa (Hymenoptera: Platygastridae) reared on Dolycoris baccarum L. (Hemiptera: Pentatomidae) egg storage at $2{ }^{\circ} \mathrm{C}$ did not affect host suitability after up to two months of storage, again with no effects on sex ratio for any storage period tested (Mahmoud and Lim 2007). 
The reduction of the percentage of hatched $T$. peregrinus nymphs from host eggs stored for 14 days at $5{ }^{\circ} \mathrm{C}$ agrees with that reported for Dolycoris baccarum L. (Hemiptera: Pentatomidae) eggs stored for 15 days at $2.1 \pm 0.7{ }^{\circ} \mathrm{C}$ (Mahmoud and Lim 2007) and Riptortus Pedestris (Fabricius) (Hemiptera: Alydidae) stored for 30 days at $10{ }^{\circ} \mathrm{C}$ (Mainali and Lim 2013). Similar parasitism rates on eggs after storage at $5{ }^{\circ} \mathrm{C}$ demonstrates that $T$. peregrinus egg quality is maintained in one-day old eggs after 12 days of storage at $5{ }^{\circ} \mathrm{C}$. Mass rearing of natural enemies is a complex and important process in biological control programs. The use of up to three-day old $T$. peregrinus eggs, on paper towel stored at $5{ }^{\circ} \mathrm{C}$ for 14 days did not affect the biological parameters of $C$. nockae and should be used for mass rearing of this parasitoid. Therefore, oviposition substrate, age, and low temperature storage of $T$. peregrinus eggs are important for rearing and in strategies making use of $C$. noackae for the biological control of $T$. peregrinus.

Acknowledgements We are grateful to Conselho Nacional de Desenvolvimento Científico e Tecnológico (CNPq) (Project: 142131/2012-1 e 445512/2014-8), Empresa Brasileira de Pesquisa Agropecuária (EMBRAPA), Coordenação de Aperfeiçoamento de Pessoal de Nível Superior (CAPES), Fundação de Amparo a Pesquisa do Estado de Minas Gerais (FAPEMIG) and the Programa Cooperativo sobre Proteção Florestal/PROTEF of Instituto de Pesquisas e Estudos Florestais/IPEF for their financial support. Dr. Phillip John Villani (The University of Melbourne, Australia) revised and corrected the English language used in this manuscript.

\section{References}

Alim MA, Lim UT (2009) Refrigeration of Riptortus clavatus (Hemiptera: Alydidae) eggs for the parasitization by Gryon japonicum (Hymenoptera: Scelionidae). Biocontrol Sci Technol 19:315-325

Ayvaz A, Karasa E, Karaborklu S, Tuncbilek A (2008) Effects of cold storage, rearing temperature, parasitoid age and irradiation on the performance of Trichogramma evanescens Westwood (Hymenoptera: Trichogrammatidae). J Stored Prod Res 44:232-240

Barbosa LR, Santos F, Buhrer CB, Nichele LA, Wilcken CF, Soliman EP (2016) Criação massal do percevejo bronzeado, Thaumastocoris peregrinus: Carpinteiro and Dellapé, 2006 (Hemiptera, Thaumastocoridae). Brasília, DF. Available in: http://ainfo.cnptia.embrapa.br/digital/bitstr eam/item/145907/1/Criacao-massal-do-percevejo-bronzea do.pdf. Accessed 02 Dec 2017

Barbosa LR, Rodrigues AP, Soler LS, Fernandes BV, Castro BMCC, Wilcken CF, Zanuncio JC (2017) Establishment in the field of Cleruchoides noackae (Hymenoptera:
Mymaridae), an exotic egg parasitoid of Thaumastocoris peregrinus (Hemiptera: Thaumastocoridae). Fla Entomol 100:372-374

Bonte M, De Clercq P (2010) Impact of artificial rearing systems on the developmental and reproductive fitness of the predatory bug Orius laevigatus. J Insect Sci 10:1-11

Brodeur J, Boivin G (2004) Functional ecology of immature parasitoids. Annu Rev Entomol 49:27-49

Castañé AC, Zapata R (2005) Rearing the predatory bug Macrolophus caliginosuson a meat-based diet. Biol Control 34:66-72

Chen WL, Leopold RA (2007) Progeny quality of Gonatocerus ashmeadi (Hymenoptera: Mymaridae) reared on stored eggs of Homalodisca coagulata (Hemiptera: Cicadellidae). J Econ Entomol 100:685-694

Colazza S, Cusumano A, Giudice DL, Peri E (2014) Chemoorientation responses in hymenopteran parasitoids induced by substrate-borne semiochemicals. BioControl 59:1-17

Constant B, Grenier S, Bonnot G (1996) Artificial substrate for egg laying and embryonic development by the predatory bug Macrolophus caliginosus (Heteroptera: Miridae). Biol Control 7:140-147

Corrêa-Ferreira BS, Moscardi F (1993) Storage techniques of stink bug eggs for laboratory production of the parasitoid, Trissolcus basalis (Wollaston). Pesqui Agropecu Bras 28:1247-1253

De Puysseleyr V, De Man S, Höfte M, De Clercq P (2013) Plantless rearing of the zoophytophagous bug Nesidiocoris tenuis. BioControl 58:205-213

De Puysseleyr V, Höfte M, De Clercq P (2014) Continuous rearing of the predatory anthocorid Orius laevigatus without plant materials. J Appl Entomol 138:45-51

Demétrio CGB, Hinde J (1997) Half-normal plots and overdispersion. GLIM Newsletter 27:19-26

Demétrio CGB, Hinde J, Moral RA (2014) Models for overdispersed data in entomology. In: Ferreira CP, Godoy WAC (eds) Ecological modelling applied to entomology. Entomology in focus. Springer, Cham, pp 219-259

Elliott JM (2003) A comparative study of the functional response of four species of carnivorous stoneflies. Freshwater Biol 48:191-202

Fatouros NE, Dicke M, Mumm R, Meiners T, Hilker M (2008) Foraging behavior of egg parasitoids exploiting chemical information. Behav Ecol 19:677-689

Foerster LA, Doetzer AK, Castro LCF (2004) Emergence, longevity and fecundity of Trissolcus basalis and Telenomus podisi after cold storage in the pupal stage. Pesqui Agropecu Bras 39:841-845

Greco CF, Stilinovic D (1998) Parasitization performance of Trichogramma spp. (Hym., Trichogrammatidae) reared on eggs of Sitotroga cerealella Oliver (Lep., Gelechiidae), stored at freezing and subfreezing conditions. J Appl Entomol 122:311-314

Hassell MP (2000) Host-parasitoid population dynamics. J Anim Ecol 69:543-566

Hinde J, Demétrio CGB (1998) Overdispersion: model and estimation. Comput Stat Data Anal 27:151-170

Hothorn T, Bretz F, Westfall P (2008) Simultaneous inference in general parametric models. Biom J 50:346-363

Huber JT (1986) Systematics, biology, and hosts of the Mymaridae and Mymarommatidae (Insecta: 
Hymenoptera): 1758-1984. In: Thomas DE (ed) Entomography: an annual review for biosystematics. Entomography Publications, Sacramento, pp 185-243

Huber JT, Mendel Z, Protasov A, LaSalle J (2006) Two new Australian species of Stethynium (Hymenoptera: Mymaridae), larval parasitoids of Ophelimus maskelli (Ashmead) (Hymenoptera: Eulophidae) on Eucalyptus. J Nat Hist 40:1909-1921

Irvin NA, Hoddle MS (2005) Determination of Homalodisca coagulata (Hemiptera: Cicadellidae) egg ages suitable for oviposition by Gonatocerus ashmeadi, Gonatocerus triguttatus, and Gonatocerus fasciatus (Hymenoptera: Mymaridae). Biol Control 32:391-400

Jacobs DH, Neser S (2005) Thaumastocoris australicus Kirkaldy (Heteroptera: Thaumastocoridae): a new insect arrival in South Africa, damaging to Eucalyptus trees: research in action. S Afr J Sci 101:233-236

Kant R, Minor MA (2017) Parasitoid Diaeretiella rapae (Hymenoptera: Braconidae) adjusts reproductive strategy when competing for hosts. Environ Entomol 46:521-527

King BH (1987) Offspring sex ratios in parasitoid wasps. Q Rev Biol 62:367-396

Ko K, Liu Y, Hou M, Babendreier D, Zhang F, Song K (2014) Evaluation for potential Trichogramma (Hymenoptera: Trichogrammatidae) strains for control of the striped stem borer (Lepidoptera: Crambidae) in the Greater Mekong subregion. J Econ Entomol 107:955-963

Kristoffersen AB, Lingjaerde C, Stenseth NC, Shimada M (2001) Non-parametric modeling of non-linear density dependence: a three-species host-parasitoid system. J Anim Ecol 70:808-819

Laudonia S, Sasso R (2012) The bronze bug Thaumastocoris peregrinus: a new insect recorded in Italy, damaging to Eucalyptus trees. Bull Insectol 65:89-93

Lin NQ, Huber JT, La Salle J (2007) The Australian genera of Mymaridae (Hymenoptera: Chalcidoidea). Zootaxa 1596:1-111

Liu SS, Zhang GM, Zhang F (1998) Factors influencing parasitism of Trichogramma dendrolimi on eggs of the Asian corn borer, Ostrinia furnacalis. Biol Control 42:273-287

Liu K, Fu B, Lin J, Fu Y, Peng Z, Jin Q (2014) Effect of temperatures and cold storage on performance of Tetrastichus brontispae (Hymenoptera: Eulophidae), a parasitoid of Brontispa longissima (Coleoptera: Chrysomelidae). J Insect Sci 14:1-6

Lundgren JG (2011) Reproductive ecology of predaceous Heteroptera. Biol Control 59:37-52

Lynch LD, Bowers G, Begon M, Thompson DJ (1998) A dynamics refuge model and population regulation by insect parasitoids. J Anim Ecol 67:270-279

Lytle JL, Morse JG, Triapsitsyn S (2012) Biology and host specificity of Gonatocerus deleoni (Hymenoptera: Mymaridae), a potential biocontrol agent of Homalodisca vitripennis (Hemiptera: Cicadellidae) in California, USA. BioControl 57:61-69

Mahmoud AMA, Lim UT (2007) Evaluation of cold-stored eggs of Dolycoris baccarum (Hemiptera: Pentatomidae) for parasitization by Trissolcus nigripedius (Hymenoptera: Scelionidae). Biol Control 43:287-293

Mainali BP, Lim UT (2013) Quality assessment of Riptortus pedestris (Hemiptera: Alydidae) eggs cold-stored at different temperature and relative humidity regime. Biol Control 64:132-137

Millar JG, Paine TD, Hoddle M (2000) Biological control of a newly introduced pest, the eucalyptus tortoise beetle, Trachymela sloanei. University of California, Division of Agriculture and Natural Resources Slosson Report, Davis, pp 1999-2000

Mutitu EK, Garnas JR, Hurley BP, Wingfield MJ, Harney M, Bush SJ, Slippers B (2013) Biology and rearing of Cleruchoides noackae (Hymenoptera: Mymaridae), an egg parasitoid for the biological control of Thaumastocoris peregrinus (Hemiptera: Thaumastocoridae). J Econ Entomol 106:1979-1985

Pak GA, Buis CEM, Heck ICC, Hermans MLG (1986) Behavioural variations among strains of Trichogramma spp.: host-age selection. Entomol Exp Appl 40:247-258

Parra JRP (2010) Mass rearing of egg parasitoids for biological control programs. In: Cônsoli FL, Parra JRP, Zucchi RA (eds) Egg parasitoids in agroecosystems with emphasis on Trichogramma. Springer, Heidelberg, pp 267-292

Pereira FF, Zanuncio JC, Serrão JE, Zanuncio TV, Pratissoli D, Pastori PL (2010) The density of females of Palmistichus elaeisis Delvare and LaSalle (Hymenoptera: Eulophidae) affects their reproductive performance on pupae of Bombyx mori L. (Lepidoptera: Bombycidae). An Acad Bras Cienc 82:323-331

Peverieri GS, Furlan P, Benassai D, Caradonna S, Strong WB, Roversi PF (2013) Host egg age of Leptoglossus occidentalis (Heteroptera, Coreidae) and parasitism by Gryon pennsylvanicum (Hymenoptera, Platygastridae). J Econ Entomol 106:633-640

Peverieri GS, Furlan P, Benassai D, Strong WB, Roversi PF (2015) Long-term storage of eggs of Leptoglossus occidentalis for the mass-rearing of its parasitoid Gryon pennsylvanicum. BioControl 60:293-306

Pizzol J, Desneux N, Wajnberg E, Thiéry D (2012) Parasitoid and host ages have independent impact on various biological traits in a Trichogramma species. J Pest Sci 85:489-496

Pratissoli D, Zanuncio JC, Vianna UR, Andrade JS, Guimarães EM, Espindula MC (2004) Fertility life table of Trichogramma pretiosum and Trichogramma acacioi on eggs of Anagasta kuehniella at different temperatures. Pesqui Agropecu Bras 39:193-196

R Core Team (2016) R: a language and environment for statistical computing. R foundation for statistical computing, Vienna, Austria. https://www.r-project.org/

Reis AR, Ferreira L, Tomé M, Araújo C, Branco M (2012) Efficiency of biological control of Gonipterus platensis (Coleoptera: Curculionidae) by Anaphes nitens (Hymenoptera: Mymaridae) in cold areas of the Iberian Peninsula: implications for defoliation and wood production in Eucalyptus globulus. For Ecol Manage 270:216-222

Schmidt JM (1994) Host recognition and acceptance by Trichogramma. In: Wajnberg E, Hassan SA (eds) Biological control with egg parasitoids. CAB International, Wallingford, pp 165-200

Silva RB, Zanuncio JC, Serrão JE, Lima ER, Figueiredo MLC, Cruz I (2009) Suitability of different artificial diets for development and survival of stages of the predaceous 
ladybird beetle Eriopis connexa. Phytoparasitica 37:115-123

Song LW, Wen XY, Zang LS, Ruan CC, Shi SS, Shao XW, Zhang F (2015) Parasitism and suitability of different egg ages of the Leguminivora glycinivorella (Lepidoptera: Tortricidae) for three indigenous Trichogramma species. J Econ Entomol 108:933-939

Sousa JM, Spence JR (2001) Host age and parasitism by Tiphodytes gerriphagus (Hymenoptera: Scelionidae), an egg parasitoid of water striders (Heteroptera: Gerridae). Ann Entomol Soc Am 94:681-685

Souza AR, Candelaria MC, Barbosa L, Wilcken CF, Campos JM, Serrão JE, Zanuncio JC (2016) Longevity of Cleruchoides noackae (Hymenoptera: Mymaridae), an egg parasitoid of Thaumastocoris peregrinus (Hemiptera: Thaumastocoridae), with various honey concentrations and at several temperatures. Fla Entomol 99:33-37

De Carvalho Spínola-Filho PR , Leite GLD, Soares MA, Alvarenga AC, De Paulo PD, Tuffi-Santos LD, Zanuncio JC (2014) Effects of duration of cold storage of host eggs on percent parasitism and adult emergence of each of ten Trichogrammatidae (Hymenoptera) species. Fla Entomol 97(1):14-21

St-Onge M, Cormier D, Todorova S, Lucas E (2016) Conservation of Ephestia kueniella eggs as hosts for Trichogramma ostriniae. J Appl Entomol 140:218-222

Strand MR (1986) The physiological interactions of parasitoids with their hosts and their influence on reproductive strategies. In: Waage J, Greathead D (eds) Insect Parasitoids. Academic Press, London, pp 97-136

Vet LEM, Dicke M (1992) Ecology of infochemical use by natural enemies in a tritrophic context. Annu Rev Entomol 37:141-172

Vinson SB (1998) The general host selection behavior of parasitoid Hymenoptera and a comparison of initial strategies utilized by larvaphagous and oophagous species. Biol Control 11:79-96

Zhang JJ, Ren BZ, Yuan XH, Zang LS, Ruan CC, Sun GZ, Shao XW (2014) Effects of host-egg ages on host selection and suitability of four Chinese Trichogramma species, egg parasitoids of the rice striped stem borer, Chilo suppressalis. BioControl 59:159-166

Zhou Y, Abram PK, Boivin G, Brodeur J (2014) Increasing host age does not have the expected negative effects on the fitness parameters of an egg parasitoid. Entomol Exp Appl 151:106-111

Leonardo Rodrigues Barbosa is researcher of the Brazilian Agricultural Research Corporation and conducts research on biological control of Eucalyptus pests.

Ângelo Peruffo Rodrigues works on biological control of forest pests using parasitoids ( $2^{\text {nd }}$ year in MSc program).

Lohana Neves de Souza works with insect rearing techniques in the laboratory.

Luís Amilton Foerster is full professor at the Universidade Federal do Paraná, Brazil with research focusing on integrated control of pests of soybean, corn and wheat and bioecology of natural enemies.

Amanda Rodrigues de Souza works with biological control of forest pests and host-parasitoid interaction.

Bárbara Monteiro de Castro e Castro works on biological control of agricultural and forest pests using predator bugs and Bacillus thuringiensis $\left(3^{\text {rd }}\right.$ year in $\mathrm{PhD}$ program).

Carlos Frederico Wilcken is associated professor at the Universidade Estadual Paulista "Júlio de Mesquita Filho" whose research focuses on biological control of native and forest pests.

José Cola Zanuncio is a full professor at the Universidade Federal de Viçosa, Brazil, with research focusing primarily on biological control of agricultural and forest pests using predatory bugs and parasitoids. 